\title{
Proceeding
}

Supplementary Issue: Spring Conferences of Sports Science. Costa Blanca Sports Science Week, 26-28 April 2018. Calpe. Alicante, Spain

\section{Anthropometrics characteristics and jumping ability in basketball}

\author{
GAETANO ALTAVILLA1 ${ }^{1}$, TIZIANA D'ISANTO², PIO ALFREDO DI TORE² \\ ${ }^{1}$ Faculty of Kinesiology, University of Split, Split, Croatia \\ ${ }^{2}$ MIUR Campania, Italy
}

\begin{abstract}
The basketball is a situational sport classified among activities laying on alternative aerobe and anaerobic processes, with an important participation of the muscular mass and an accentuated prevalence of the alactacid anaerobic process. The purpose of this work is to analyze and evaluate the correlations between the various variables of an anthropometric character and the differences in performance between the roles, testing a group of senior high-level basketball players, subdividing them according to their role within of the team. Data were collected by 40 basketball players (Senior elite), divided into four groups: Power Forward $(n=12 ;$ age = 24.5 + 1.4 y.), Pivot $(n=12$; age 24.1 + 1.1 y.); Playmaker/Guard $(n=8 ;$ age $=24.4+1.3$ y. $)$, and Small Forward $(n=8$; age $=23.5+1.2$ y.). Morphological data were height, weight, body mass index (BMI), Abalakov test modified. The explosive strength was measured with the method of Bosco: squat jump (SJ), counter movement jump (CMJ) and CMJ with arms (CMJas). Jumping performance and of coordination was determined through the difference between the measurement on the technical action of the shot block with one hand $(\mathrm{St})$ and the height with one stretched arm (AB1); then, the measurement of the technical action of the rebound at two hands $(\mathrm{Rb})$ and the height with two stretched arms (AB2). The results of the anthropometric parameters showed significant differences in height $(F=4.75, p<0.006)$, height with a stretched $\operatorname{arm} A B 1(F=3.60 ; p<0.02)$ and height with two stretched arms $A B 2(F=3.66 ; p<0.02)$. In the comparison by role we did not obtain any statistical significance regarding the Bosco test. Results of Abalakov test modified showed significant differences in St $(F=7.29 ; p<.001)$ and in $\mathrm{Rb}(F=3,95 ; p<0.01)$. With the Bosco test the information obtained concerns the assessment of the athlete's jumping capacity not related to specific technical gestures; differently with the Abalakov Test, has provided precise indications on the elevation abilities connected to the technical gesture of the blocked shot and of the rebound. A high correlation was found between the results of the anthropometric parameters and those of the Abalakov test. In senior high-level basketball, the anthropometric profile of the players is directly related to specific variables

Corresponding author. Faculty of Kinesiology, University of Split, Split, Croatia. http://orcid.org/0000-0001-8436-7819

E-mail: gaetano.altavilla_@libero.it

Supplementary Issue: Spring Conferences of Sports Science. Costa Blanca Sports Science Week, 26-28 April 2018. Calpe. Alicante, Spain.

JOURNAL OF HUMAN SPORT \& EXERCISE ISSN 1988-5202

(c) Faculty of Education. University of Alicante

doi: 10.14198/jhse.2018.13.Proc2.22
\end{abstract}


which must be used for training planning and for the choice of players in setting up a team. Modern basketball, due to the increasing intensity of the game rhythm, increasingly engages the anaerobic alactacid component; it is above all for this reason that we need more and more powerful athletes, who are both fast and capable of high performance in jumps. This is the reason why assessment, training and continuous monitoring of jumping skills are a decisive aspect of performance. Key words: BASKETBALL ELITE, JUMPING TEST, ABALAKOV TEST MODIFIED, MONITORING AND EVALUATION.

\section{Cite this article as:}

Altavilla, G., D'Isanto, T., \& Di Tore, P. (2018). Anthropometrics characteristics and jumping ability in basketball. Journal of Human Sport and Exercise, 13(2proc), S385-S392. doi:https://doi.org/10.14198/jhse.2018.13.Proc2.22 


\section{INTRODUCTION}

Basketball is a sport of the situation (Raiola, 2015), for sports situation means all those sports in which it is not possible to predetermine the actions that will occur in the development of the game (Altavilla \& Raiola, 2014). Sports activities such as basketball include all the educational and training features required for the development of athletes (Altavilla et al, 2018, Raiola D'Isanto, 2016b). Competitive basketball is an intermittent high-intensity physical activity that requires a well developed aerobic and anaerobic fitness and it is featured from activity of short time at high intensity (Castagna et al, 2008). This type of commitment in basketball increases the anaerobic alactacid commitment (Gaetano \& Rago, 2014), so the training of aerobic capacity is not specific and contraindicated (Katch \& Weltman, 1979). In modern basketball the speed of play is a clear sign of a greater demand for physical strength and the speed of the technical gesture; in fact, in the activity of training and selection of the players to set up a winning team the explosive dynamic strength, the elevation and the speed of displacement are selective and determining (Ashley \& Weiss, 1994). Physical demands during the match differ from each playing position (Altavilla et al, 2017). Coaches involved in training of the players should take in account for these positional variations in distance covered in order to design position-specific physical drills (Rago et al, 2017). For basketball, in accord to the analysis given by Professor Dal Monte (1969), is classified as a sport in which they are considered, in addition to matters bioenergy (commitment cardiovascular and type of mainly energy system), also aspects of the biomechanics of muscle under both aerobic and anaerobic energy (Altavilla \& Raiola, 2015) and in different proportions depending on the intensity, of the density, of the volume of the charge, of the frequency (Bompa \& Haff, 2009; Raiola \& D'Isanto, 2016a). The analysis of the workload during the competition is today fundamental for the planning of training (Altavilla \& Raiola, 2018; Carlomagno et al, 2010), since currently physical conditioning is increasingly characterized by the integration of exercises that reproduce specific technicaltactical gestures (Bosco et al, 1994). The performance is also linked to other qualities such as neuromuscular coordination, motor control (Raiola, 2017; Raiola \& Di Tore, 2017), tactical attitudes and motivational characteristics (Raiola, 2014). The purpose of this work is to analyze and evaluate the correlations between the various variables of an anthropometric features and the differences in performance between the roles, testing a group of senior high-level basketball players, subdividing them according to their role within of the team.

\section{MATERIALS AND METHODS}

\section{Subjects}

40 male basketball players took part in this study with experience of at least 8 years of competitive activity and perform on average 5 training sessions per week. The tests were carried out on a group of athletes participating in the second division Italian league. The basketball players were divided into four groups according to their role: Power Forward, n.12; age: $24.5 \pm 1.4$ years, Pivot, n.12; age: $24.1 \pm 1.1$ years, Playmaker/Guard, n.8; age: $24.4 \pm 1.3$ years and Small Forward, n.8; age: $23.5 \pm 1.2$ years.

\section{Details on experimental procedure}

An evaluation of the anthropometric parameters was carried out considering the following variables: height $(\mathrm{cm})$, weight $(\mathrm{kg})$, body mass index (BMI): $\mathrm{kg} / \mathrm{m}^{2}$ and measurements of the height reached at the maximum extension of one arm (AB1 in $\mathrm{cm}$ ) and two arms (AB2 in $\mathrm{cm}$ ). The second type of data concerns the analysis of jump capacities. To obtain this information we used two detection systems that evaluate the general jump capacity thanks to the indirect measurement of the explosive strength obtained with the Bosco Test and the elevation capabilities using the Abalakov test modified. With the Abalakov test the measurement of the height reached with a stretched arm (AB1) and after a jump with a run-up step (St) was detected; also the height 
reached by stretching both arms (AB2), and after a from standstill jump (Rb). Each player simulates the technical action of the rebound from standstill $(\mathrm{Rb})$ and the technical action of the shot block (St). For each test three tests are carried out: of the jumps performed only the best result will be considered for the statistical analysis. Evaluating the results obtained by the difference between the measure of the attack action of the blocked shot (St) and the measure reached by extending an arm (AB1), between the technical action of the rebound from standstill $(\mathrm{Rb})$ and the measure reached by extending both upper limbs (AB2). In this way it was possible to calculate the elevations obtained by the various players jumping from standstill and moving. The result in $\mathrm{cm}$ of elevation with use of the movement, (difference in movement, DM), is obtained from the difference between St and AB1 while that from standstill (difference without movement, DWM) corresponds to the difference between $\mathrm{Rb}$ and $\mathrm{AB} 2$. Other data that we have obtained concern the difference between the two evaluated elevation forms (DM-DWM = Diff in $\mathrm{cm}$ ). With the Bosco method the height reached is measured by performing jumps with different techniques. Each test is characterized by the execution of three jumps: for the statistical survey the best result is considered. It consists in the indirect evaluation of the dynamic-explosive strength and of the explosive strength through calculation of the vertical displacement of the center of gravity with the Bosco method (Bosco et al, 1983). The players perform a series of jumps that provide data subsequently processed by a software program that calculates the contact and flight times in milliseconds, the heights in centimeters and the powers in Watts. In this study, only three tests of the test battery developed by Bosco were used: the Squat Jump (SJ), the Counter Movement Jump (CMJ), the Counter Movement Jump with the use of the arms (arms) and CMJ as. The difference in $\mathrm{cm}$ obtained from the results of the CMJ and the SJ (CMJ-SJ). This value gives indications on the ability of the subject to use elastic energy (Bobbert et al, 1996; Komi \& Bosco, 1978). In the first test, Squat Jump (SJ), each player performs a vertical jump starting from a position with lower limbs bent at $90^{\circ}$ with his hands on his hips, without making any counter-movement downwards. The Squat-Jump allows to evaluate the explosive strength of the lower limbs. In the second test that of the Counter Movement Jump (CMJ), a vertical jump is performed, starting from an upright position, with the hands on the hips, performing a counter-movement of the lower limbs downward, until reaching a bending of about $90^{\circ}$ with explosive muscle activation. From the difference of the results of the first two tests (CMJ-SJ) a value is obtained that represents an index to evaluate the elasticity of the extensor muscles of the lower limbs. The third test is represented by the CMJ as, characterized by a jump with counter-movement, with the use of the upper limbs.

\section{Statistics analysis}

Data on the anthropometric characteristics and results of the Bosco test and the modified Abalakov test are presented as mean and standard deviation (SD). For the comparison of the anthropometric data and jumping ability according to the role is the analysis of variance was performed. The correlations between all the variables considered were calculated using the Pearson correlation coefficient. Prior to each statistical analysis the homogeneity of variance was verified with Bartlett's test, and the normality of distribution of each variable was tested with the Shapiro-Wilk test. Statistical analysis was performed using SPSS 22.0 (SPSS Inc., Chicago, IL, USA). For all the performed analyses, a $P$-value $<0.05$ was considered significant.

\section{RESULTS}

The tables 1 and 2 present the mean and standard deviation of anthropometric values and jumping ability of all basketball players considered. The results of the comparison of the anthropometric parameters and jumping ability according to the role, are indicated in table 3 . With regard to the anthropometric data, we obtained significant results for the height $(F=4.75 ; p<0.006), A B 1$ measures with a stretched arm $(F=3.60$; $p<0.02)$ and $A B 2$ measures with two outstretched arms $(F=3.66 ; p<0.02)$. The Pivot group $(P)$ achieved higher values of the playmakers / guards (P/G): height (P: $200.2 \pm 5.1 \mathrm{~cm}$ vs $P$ / G: $190.1 \pm 3.8 \mathrm{~cm} ; p<$ 
0.01), AB1 ( $P: 263.5 \pm 6.8 \mathrm{~cm}$ vs P / G: $253.2 \pm 5.2 \mathrm{~cm} ; \mathrm{p}<0.01$ and $A B 2$ (P: $258.5 \pm 6.3 \mathrm{~cm}$ vs P / G: $249.5 \pm$ $4.5 \mathrm{~cm}, p<0.05)$ In the comparison by role we did not obtain any statistical difference regarding the Bosco test. The results of the modified Abalakov test instead show significant variations for as regards the St $(F=$ $7.29 ; p<0.001)$ and the $R b(F=3.95 ; p<0.01)$. The analysis of the correlation matrix shows that the height and weight are correlated with each other and also with AB1 and AB2 (table 4). As for the tests of the Bosco Test and the modified Abalakov Test, the different variables of each test are correlated with each other. With the Bosco test, the information obtained concerns the ability to jump not connected to technical gestures; differently with Abalakov Test more specific indications were found on the coordination skills linked to a technical gesture.

Table 1. Anthropometric values of all basketball players

\begin{tabular}{cc}
\hline Variables & Average \pm SD $(\boldsymbol{n}=\mathbf{4 0})$ \\
\hline Height $(\mathrm{cm})$ & $195,4 \pm 4,3$ \\
Weight $(\mathrm{kg})$ & $84,5 \pm 3,15$ \\
$\mathrm{BMI}\left(\mathrm{kg} / \mathrm{cm}^{2}\right)$ & $22,1 \pm 1,1$ \\
$\mathrm{AB1}(\mathrm{cm})$ & $257,5 \pm 7,3$ \\
$A B 2(\mathrm{~cm})$ & $254,2 \pm 7,1$ \\
\hline
\end{tabular}

Table 2. Test results of the jumping ability

\begin{tabular}{ll}
\hline Variables & Average $\pm S D(n=40)$ \\
\hline Bosco test & $38,1 \pm 3,8$ \\
SJ $(\mathrm{cm})$ & $43,2 \pm 3,9$ \\
CMJ $(\mathrm{cm})$ & $5,1 \pm 1,4$ \\
CMJ-SJ $(\mathrm{cm})$ & $50,1 \pm 4,6$ \\
CMJas $(\mathrm{cm})$ & \\
Abalakov test modified & $332,1 \pm 8,1$ \\
St $(\mathrm{cm})$ & $309,1 \pm 8,2$ \\
Rb $(\mathrm{cm})$ & $74,1 \pm 5,8$ \\
DM $(\mathrm{cm})$ & $54,2 \pm 5,9$ \\
DWM $(\mathrm{cm})$ & $19,9 \pm 5,1$ \\
Diff $(\mathrm{cm})$ &
\end{tabular}


Table 3. Comparison of the anthropometric and jump abilities variables according to the role

\begin{tabular}{lllllll}
\hline Variables & $\begin{array}{l}\text { Power Forward } \\
(\mathrm{n}=12)\end{array}$ & $\begin{array}{l}\text { Pivot } \\
(\mathrm{n}=12)\end{array}$ & $\begin{array}{l}\text { Playmaker/ Guard } \\
(\mathrm{n}=8)\end{array}$ & $\begin{array}{l}\text { Small Forward } \\
(\mathrm{n}=8)\end{array}$ & $\mathrm{F}$ & $p$ \\
\hline Height $(\mathrm{cm})$ & $198,4 \pm 4,1$ & $200,2 \pm 5,1$ & $190,1 \pm 3,8$ & $194,8 \pm 5,4$ & 4,75 & 0,006 \\
Weight $(\mathrm{kg})$ & $88,9 \pm 6,3$ & $86,3 \pm 4,9$ & $80,7 \pm 5,5$ & $84,5 \pm 8,3$ & 1,64 & 0,221 \\
BMI $(\mathrm{kg} / \mathrm{cm} 2)$ & $22,5 \pm 1,4$ & $21,5 \pm 1,3$ & $22,3 \pm 1,3$ & $22,2 \pm 1,2$ & 0,25 & 0,704 \\
AB1 $(\mathrm{cm})$ & $258,1 \pm 6,1$ & $263,5 \pm 6,8$ & $253,2 \pm 5,2$ & $257,7 \pm 6,1$ & 3,60 & 0,022 \\
AB2 $(\mathrm{cm})$ & $255,1 \pm 6,1$ & $258,5 \pm 6,3$ & $249,5 \pm 4,6$ & $254,2 \pm 6,2$ & 3,66 & 0,020 \\
SJ $(\mathrm{cm})$ & $38,7 \pm 3,8$ & $39,6 \pm 2,8$ & $37,5 \pm 5,3$ & $36,8 \pm 4,8$ & 1,03 & 0,388 \\
CMJ $(\mathrm{cm})$ & $43,8 \pm 3,9$ & $44,6 \pm 2,1$ & $41,8 \pm 5,9$ & $42,7 \pm 4,7$ & 0,72 & 0,546 \\
CMJ-SJ $(\mathrm{cm})$ & $5,1 \pm 1,6$ & $5,0 \pm 1,4$ & $4,3 \pm 1,5$ & $5,9 \pm 1,4$ & 0,24 & 2,199 \\
CMJas $(\mathrm{cm})$ & $50,6 \pm 4,5$ & $51,5 \pm 2,8$ & $49,5 \pm 6,5$ & $49,1 \pm 7,2$ & 0,70 & 0,555 \\
St $(\mathrm{cm})$ & $332,9 \pm 6,6$ & $336,7 \pm 6,4$ & $327,8 \pm 8,7$ & $328,9 \pm 2,1$ & 7,29 & 0,001 \\
Rb $(\mathrm{cm})$ & $309,8 \pm 8,7$ & $313,7 \pm 7,3$ & $305,6 \pm 8,3$ & $306,7 \pm 5,1$ & 3,95 & 0,01 \\
DM $(\mathrm{cm})$ & $74,8 \pm 4,9$ & $73,2 \pm 6,2$ & $74,6 \pm 4,0$ & $71,2 \pm 6,0$ & 2,67 & 0,061 \\
DWM $(\mathrm{cm})$ & $54,7 \pm 6,0$ & $55,2 \pm 6,9$ & $56,1 \pm 5,9$ & $52,5 \pm 2,5$ & 0,44 & 0,728 \\
Diff $(\mathrm{cm})$ & $20,1 \pm 4,6$ & $18,0 \pm 5,4$ & $18,5,0 \pm 3,7$ & $18,7 \pm 6,5$ & 1,41 & 0,253 \\
\hline
\end{tabular}

Table 4. Correlation matrix (anthropometric variables and jumping ability)

\begin{tabular}{ccccccccccc}
\hline & Height & Weight & $A B 1$ & $A B 2$ & $S J$ & $C M J$ & CMJ-SJ & CMJas & St & $R b$ \\
\hline Height & - & & & & & & & & & \\
Weight & 0,631 & - & & & & & & & & \\
AB1 & 0,860 & 0,690 & - & & & & & & & \\
AB2 & 0,873 & 0,674 & 0,990 & - & & & & & & \\
SJ & $-0,342$ & $-0,356$ & $-0,298$ & $-0,328$ & - & & & & & \\
CMJ & $-0,294$ & $-0,282$ & $-0,198$ & $-0,234$ & 0,933 & - & & & & \\
CMJ-SJ & 0,114 & 0,186 & 0,259 & 0,242 & $-0,131$ & 0,234 & - & & & \\
CMJas & $-0,274$ & $-0,239$ & $-0,250$ & $-0,296$ & 0,737 & 0,813 & 0,246 & - & & \\
St & 0,596 & 0,392 & 0,705 & 0,680 & 0,198 & 0,264 & 0,190 & 0,215 & - & \\
Rb & 0,640 & 0,442 & 0,730 & 0,707 & 0,109 & 0,245 & 0,379 & 0,107 & 0,837 & - \\
\hline
\end{tabular}

\section{DISCUSSION}

These analyzes show that the action of the arms in the jumps for the rebounds and the blocked shot, the strength developed by the lower limbs, the use of a step in the jump phase and the coordination between the movements of the arms and legs, can be decisive for assessing the potential of an athlete (Feltner et al, 1999; Harman et al, 1990). The strong correlation between St and Rb could be an indicator of an athlete's ability to transform the accumulated kinetic energy during the run-up phase into potential energy. Some indicators, such as height, $A B 1$ and AB2 for Pivot, Power Forward and Small Forward players, are related to the technical needs that depend on the evolution of the game. These players have to decrease the flight time to interfere in the increasingly fast opposing actions; a greater extension of the arms decreases the time of flight necessary to recover the ball to rebound, receive the ball from the companions or stop the opponent's ball. The correct identification of the morphological characteristics and the close connection of these with the technical role becomes fundamental to obtain significant results. The anthropometric height parameters of $A B 1$ and $A B 2$ are decisive and selective even for power forward, because they are closely related to the 
performance of jumping skills in specific gestures such as the blocked shot and the rebound, (St and Rb). The results of the battery Bosco test showed no difference between the different roles in terms of jumping ability among basketball players. These results confirm the link between the morphological characteristics, the orientation towards technical specialization in relation to the role and the training of individualized muscular qualities. The analysis of the correlation matrix (Table 5) shows that most of the anthropometric variables are correlated with each other: in particular height with weight and $A B 1$ and $A B 2$. In relation to the different parameters of the jumping ability we have verified that all anthropometric variables are positively correlated to St and $\mathrm{Rb}$, and negatively to SJ.

\section{CONCLUSIONS}

In basketball senior high level, the profile anthropometric of the players is directly linked to several variables to be used for training planning and in setting the choice of players of a team. Modern basketball, due to the increasing intensity of the game rhythm, increasingly commits the alactacid anaerobic component; it is above all for this reason that we need more and more powerful athletes, who are both fast and capable of high performance in jumps. For these reasons the evaluation, training and continuous monitoring of jumping ability are a vital aspect for the operation.

\section{REFERENCES}

Altavilla, G., Raiola, G. (2014). Global vision to understand the game situations in modern basketball, Journal of Physical Education and Sport, 14(4): 493-496.

Altavilla, G., Raiola, G. (2015). Sports game tactic in basketball, Sport Science - Vol. 8,1.

Altavilla, G., Riela, L., Di Tore, P.A., Raiola, G. (2017). The physical effort required from professional football players in different playing positions. Journal of Physical Education and Sport, Vol.17(3): 2007-2012.

Altavilla, G., \& Raiola, G. (2018). Periodization: finalization of the training units and of the load's entity, The European Proceedings of Social \& Behavioural Sciences EpSBS. ICPESK 2017 International Congress of Physical Education, Sport and Kinetotherapy, eISSN: 2357-1330.

Altavilla, G., Mazzeo, F., D'Elia, F., Raiola, G. (2018b). Physical commitment and specific work for each role in an elite soccer team, Journal of Physical Education and Sport, in press.

Altavilla, G., D'Isanto, T., Di Tore, P., \& Raiola, G. (2018). Free throw and outcomes: Pilot study on intensive training versus extensive one. Journal of Human Sport and Exercise, in press. https://doi.org/10.14198/ihse.2018.133.02

Ashley, C.D., \& Weiss, L.W. (1994). Vertical jump performance and selected physiological characteristics of women. J Strength Cond Res; 8: 5-11.

Bobbert, M.F., Gerritsen, K.G., Litjens, M.C., Van Soest, A.J. (1996). Why is countermovement jump height greater than squat jump height? Med Sci Sports Exerc, 28(11): 1402-1412. https://doi.org/10.1097/00005768-199611000-00009

Bompa, T.O., \& Haff, G.G. (2009). Periodization. Theory and Methodology of Training. II: Human Kinetics.

Bosco, C., Komi, P.V., Bosco, E., Nicol, C., Pulvirenti, G., Caruso, I. (1994). Influence of training on mechanical and biochemical profiles of athlete's muscles. Coaching and Sport Science Journal; 1,1: 8-13.

Bosco, C., Luhtanen, P., Komi, P.V. (1983). A simple method for measurement of mechanical power in jumping. Eur J Appl Physiol; 50(2):273-82. https://doi.org/10.1007/BF00422166

Carlomagno, N., Di Tore, S., Aiello, P., Raiola, G., Prosperi, R., Macchi, C. (2010) The assessmentprediction capacities of teachers during physical activities in the primary school in Italy: Analysis of 
the relationship between expected energy expenditure and actual energy expenditure during a light physical activity lasting 15 minutes, Sport Science, 3 (2).

Castagna, C., Impellizzeri, F.M., Rampini, E., D'Ottavio, S., Manzi, V. (2008). The Yo-Yo intermittent recovery test in basketball players, Journal of Science and Medicine in Sport, 11, 202-208. https://doi.org/10.1016/j.jsams.2007.02.013

Dal Monte, A. (1969). Proposta di una classificazione ad orientamento biomeccanico delle attività sportive, Med.Sport, 22.

Feltner, M.E., Fraschetti, D.J., Crisp, R.J. (1999). Upper extremity augmentation of lower extremity kinetics during countermovement vertical jumps. J Sports Sci; 17:449-66. https://doi.org/10.1080/026404199365768

Gaetano, R., Rago, V. (2014) Preliminary study on effects of hiit-high intensity intermittent training in youth soccer players Journal of Physical Education and Sport, 14 (2):148-150.

Harman, E.A., Rosenstein, M.T., Frykman, P.N., Rosenstein. R.M. (1990). The effects of arms and countermovement on vertical jumping. Med Sci Sports Exerc, 22(6):825-33. https://doi.org/10.1249/00005768-199012000-00015

Katch, V.L., \& Weltman, A. (1979). Interrelationship between anaerobic power output, anaerobic capacity and aerobic power. Ergonomics, 22(3):325- 32. https://doi.org/10.1080/00140137908924616

Komi, P.V., \& Bosco, C. (1978). Utilization of stored elastic energy in extensor muscles by men and women, Med Sci.Sports, 10: 261-265.

Rago, V., Pizzuto, F., Raiola, G., (2017). Relationship between intermittent endurance capacity and match performance according to playing position in sub-19 professional male football players: preliminary results. Journal of physical education and sport, 17(2): 688-691.

Raiola, G. (2014). Motor control and learning skills according to cognitive and ecological dynamic approach in a vision on behaviorism, cognitive, Gestalt and phenomenology theories. Mediterranean Journal of Social Sciences, 5(15): 504-506. https://doi.org/10.5901/mjss.2014.v5n15p504

Raiola, G. (2015). Basketball feint and non-verbal communication: empirical framework. Journal of Human Sport and Exercise, 10(1 proc), S360-S368. https://doi.org/10.14198/hhse.2015.10.Proc1.26

Raiola, G., D'Isanto, T., (2016a) Assessment of periodization training in soccer, Journal of Human Sport and Exercise, 11, 1 (Special issue). https://doi.org/10.14198/hihse.2016.11.Proc1.19

Raiola, G., D'Isanto, T., (2016b) Descriptive shot analysis in basketball, Journal of Human Sport and Exercise, 11, 1 (Special issue). https://doi.org/10.14198/hhse.2016.11.Proc1.18

Raiola, G., Di Tore, P.A. (2017) Motor learning in sports science: Different theoretical frameworks for different teaching methods, Sport Science, 10 suppl 1.

Raiola, G. (2017) Motor learning and teaching method, Journal of Physical Education and Sport, 17(4).

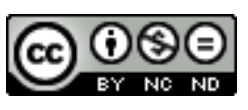

This title is licensed under a Creative Commons Attribution-NonCommercial-NoDerivs 4.0 Unported License. 